\title{
Birth Weight and Weight at 1 Year Are Independent Determinants of Bone Mass in the Seventh Decade: The Hertfordshire Cohort Study
}

\author{
ELAINE M. DENNISON, HOLLY E. SYDDALL, A. AIHIE SAYER, HELEN J. GILBODY, AND \\ CYRUS COOPER
}

MRC Epidemiology Resource Centre, University of Southampton, Southampton General Hospital, Southampton SO16 6YD, United Kingdom

\begin{abstract}
Several studies have shown relationships between growth in early life and adult bone mass; in this article, we evaluate the relative contributions of pre- and postnatal factors to bone mass in the seventh decade. A total of 498 eight men and 468 women who were born in Hertfordshire during the period 1931-1939 and still living there were recruited. Detailed birth records were available. Participants attended a clinic where they completed a detailed health questionnaire, before performance of anthropometric measurements and bone densitometry of the proximal femur and lumbar spine (Hologic QDR 4500). Birth weight was associated with bone mineral content in both men (proximal femur: $r=0.16, p=0.0003$; lumbar spine: $r=0.10, p=0.03$ ) and women (proximal femur: $r=0.16, p=0.0008$; lumbar spine: $r=0.11, p=0.03$ ); relationships with bone mineral density were weaker and were significant at the proximal femur in men only ( $p=0.03$ ). Relationships between weight at $1 \mathrm{y}$ and bone mineral content were even stronger (proximal femur: men $r=0.22, p<0.0001$; women $r=0.14, p=0.002)$. In men, $18 \%$
\end{abstract}

\section{ABSTRACT}

of the variance in proximal femoral bone area was explained by a model that included birth weight, weight at $1 \mathrm{y}$, and adult weight, with the relative contributions attributed to each being $2.8,6.8$, and $8.2 \%$, respectively. In women, similar modeling produced figures of $6.7,4.2$, and $3.9 \%$ (overall variance of $15 \%$ in proximal femoral bone area). Hence, weight at each of these three points in the life course is important in the determination of adult bone mass, with greater contributions of earlier growth to bone size and mineral content than to bone mineral density. (Pediatr Res 57: 582-586, 2005)

\section{Abbreviations}

BMAD, bone mineral apparent density BMC, bone mineral content BMD, bone mineral density BMI, body mass index DEXA, dual-energy x-ray absorptiometry HRT, hormone replacement therapy
Several epidemiologic studies from around the world have shown relationships between growth in early life and adult bone mass. Initial work in Bath (1) and Hertfordshire, UK (2), showed relationships between weight at $1 \mathrm{y}$ and adult bone mineral content (BMC), but more recent studies (3-5) have also found evidence of an association between birth weight and adult bone mass. Furthermore, a Finnish study (6) demonstrated a direct association between low birth length, poor childhood growth, and later risk for hip fracture. Hence, we sought to evaluate the relative contribution of pre- or postnatal growth to the determination of adult bone mass by using a

Received April 6, 2004; accepted August 24, 2004

Correspondence: Elaine Dennison, Ph.D., MRC Epidemiology Resource Centre, University of Southampton, Southampton General Hospital, Southampton SO16 6YD, UK; e-mail: emd@mrc.soton.ac.uk.

This study was conducted with support from the Medical Research Council and Arthritis Research Campaign.

DOI: 10.1203/01.PDR.0000155754.67821.CA larger birth cohort of men and women who were born in Hertfordshire in the 1930s and still resident there, for whom extensive childhood records, including birth weight and weight at $1 \mathrm{y}$, were available.

\section{METHODS}

A total of 768 men and 714 women who were aged 60-75 y completed this study, based around East Hertfordshire. The selection procedure for these individuals was as follows: in brief, with the help of the National Health Service Central Registry at Southport and Hertfordshire Family Health Service Association, we traced men and women who were born during 1931-1939 in Hertfordshire and still lived there during the period 1998-2003. The birth weight and weight at $1 \mathrm{y}$ of age of each individual had been recorded in a ledger by a team of midwives and health visitors who had attended each birth in Hertfordshire in the 1930s and visited the child's home at intervals during the first year of life. After obtaining written permission from each person's general practitioner, we approached each person by letter, asking them whether they would be willing to be contacted by one of our research nurses. When they agreed, a research nurse performed a home visit, at which the nurse administered a structured questionnaire. This included information on socioeconomic status, medical history, cigarette smoking, alcohol consumption, dietary cal- 
cium intake, and reproductive variables in women. Physical activity was assessed by a previously validated questionnaire (7). The participant then was invited to attend a local clinic.

Height was measured to the nearest $0.1 \mathrm{~cm}$ using a Harpenden pocket stadiometer (Chasmors Ltd, London, UK), and weight was measured to the nearest $0.1 \mathrm{~kg}$ on a SECA floor scale (Chasmors). Body mass index (BMI) was calculated as weight divided by height ${ }^{2}\left(\mathrm{~kg} / \mathrm{m}^{2}\right)$. Waist (midway between the costal margin and the iliac crest in the midaxillary line) and hip (greatest diameter around the gluteal region) circumferences were measured with steel tape, and skinfold thickness was determined at four sites (biceps, triceps, subscapular, and suprailiac) using a Harpenden skinfold caliper (Chasmors).

Bone mineral content (BMC), bone area, and bone mineral density (BMD) were measured in a subgroup of 498 men and 468 women by dual-energy x-ray absorptiometry (DEXA) at the lumbar spine and proximal femur (neck, total, intertrochanteric, and trochanteric regions, Wards triangle) using a Hologic QDR 4500 instrument. Volumetric bone density, known as bone mineral apparent density (BMAD), was estimated using the method of Carter et al. (8). Measurement precision error, expressed as coefficient of variation, was $1.55 \%$ for lumbar spine BMD, $1.45 \%$ for total femur BMD, and $1.83 \%$ for femoral neck BMD for the Hologic QDR 4500; these figures were obtained by 25 volunteers who were not part of the study and were undergoing two scans on the same day, getting on and off the table between examinations. Short-term (2 mo) precision error for the QDR 4500 was $<1 \%$ for both sites (manufacturer's figures). Individuals who were taking drugs that are known to alter bone metabolism (e.g. bisphosphonates) were excluded from this part of the study, although women who were taking hormone replacement therapy (HRT) were allowed to participate. There were no other exclusion criteria to this part of the study, and participants were approached for consent as they attended clinic.

Ethical permission for the study was granted by the East and North Hertfordshire Ethical Committees. All participants gave written informed consent.

Normality of variables was assessed and variables were transformed as required. The Stata statistical software package was used for the analyses. Pearson correlations and ANOVAs, followed by multiple linear regression models, were used to explore the role of lifestyle and anthropometric factors in determining bone mass. An unconditional centile for growth in the first year of life was calculated, before the calculation of centiles for weight at $1 \mathrm{y}$ conditional on birth weight according to the methods of Cole (9). This allowed us to examine relationships between adult bone mass and conditional centile for growth in the first year of life, conditional on centile at birth, hence accounting for regression to the mean in weights from birth to $1 \mathrm{y}$ of age. Analysis of variance using type I sum of squares was used to partition the effects of weight through the life course on adult bone mass.

\section{RESULTS}

The characteristics of the study population at baseline are displayed in Table 1. The mean age of the men and women studied was 64.8 and $66.4 \mathrm{y}$, respectively. Thirty-four percent

Table 1. Summary characteristics of study participants

\begin{tabular}{|c|c|c|}
\hline $\begin{array}{c}\text { Characteristic } \\
\text { [mean (SD) unless stated otherwise] }\end{array}$ & $\begin{array}{c}\text { Men } \\
(n=498)\end{array}$ & $\begin{array}{l}\text { Women } \\
(n=468)\end{array}$ \\
\hline Age (y) & $64.8(2.5)$ & $66.4(2.6)$ \\
\hline BMI $\left(\mathrm{kg} / \mathrm{m}^{2}\right)^{\mathrm{a}}$ & $26.6(1.1)$ & $26.8(1.2)$ \\
\hline Alcohol consumption (units per week) & $10.0(3.0,22.5)$ & $2.5(0.5,7.0)$ \\
\hline Habitual activity $(\%)^{\mathrm{c}}$ & $64.0(14.8)$ & $61.3(14.9)$ \\
\hline $\begin{array}{l}N(\%) \text { Current manual social class } \\
\text { IIIM- } \mathrm{V}^{\mathrm{d}}\end{array}$ & $277(55.6)$ & $286(61.1)$ \\
\hline $\begin{array}{l}N(\%) \text { Current nonmanual social class } \\
\text { I-IIIN }^{\mathrm{d}}\end{array}$ & $193(38.8)$ & $182(38.9)$ \\
\hline Lumbar spine BMD $\left(\mathrm{g} / \mathrm{cm}^{2}\right)$ & $1.08(0.16)$ & $0.96(0.17)$ \\
\hline Femoral neck BMD $\left(\mathrm{g} / \mathrm{cm}^{2}\right)$ & $0.85(0.12)$ & $0.76(0.12)$ \\
\hline Total femoral BMD $\left(\mathrm{g} / \mathrm{cm}^{2}\right)$ & $1.04(0.13)$ & $0.90(0.13)$ \\
\hline \multicolumn{3}{|c|}{$\begin{array}{l}\text { a Geometric mean and SD. } \\
\text { b Median and IQR among drinkers. Twenty men and } 86 \text { women stated that } \\
\text { hey do not drink alcohol. } \\
{ }^{c} \text { Standardized score ranging } 0-100 \text { derived from frequency of gardening, } \\
\text { ousework, climbing stairs, and carrying loads in a typical week. Higher scores } \\
\text { ndicate greater level of activity. } \\
{ }^{d} \text { Social class was unclassified for } 26 \text { men. }\end{array}$} \\
\hline
\end{tabular}

of the men and $62 \%$ of the women had never smoked, whereas $52 \%$ of the men $(28 \%$ of the women) and $15 \%$ of the men $(10 \%$ of the women) were ex-smokers and current smokers, respectively. Four percent of men and $18 \%$ of women were nondrinkers, whereas $21 \%$ of men and $12 \%$ of women were moderate drinkers (i.e. 11-21 units per week for men, 8-14 units per week for women). Twenty-five percent of men and $3 \%$ women consumed greater that the recommended number of units of alcohol per week ( $>21$ units per week for men, $>14$ units per week for women). A total of 274 (59\%) women in this cohort had never used HRT, $86(18 \%)$ had discontinued use $>5 \mathrm{y}$ before they were seen as part of this study, $29(6 \%)$ had stopped within the last $5 \mathrm{y}$, and $79(17 \%)$ were still taking HRT at the time of their clinic visit. Participants who participated in the DEXA substudy did not significantly vary from the clinic population as a whole with regard to birth weight or weight at $1 \mathrm{y}$, age, social class, cigarette and alcohol consumption, height, weight, or BMI. Although those who participated in the study as a whole tended to be slightly heavier at birth and at $1 \mathrm{y}$ of age than those who declined to participate in any part of the study, these differences were not statistically significant.

In this cohort, BMC at all sites, particularly at the femur region, was strongly associated with adult anthropometric measures, including height ( $p<0.001)$, weight $(p<0.001)$, and all skinfold measurements $(p<0.005)$. Relationships with BMD were similar and only marginally weaker. Adjustment for age, cigarette and alcohol consumption, physical activity, social class, HRT use, and years since menopause in women in a multiple regression model made little difference to our results. In this cohort, there were no significant relationships observed between either BMC or BMD with age, physical activity, cigarette or alcohol consumption, or social class on univariate analysis.

Birth weight was significantly associated with spine BMC (men; $r=0.10, p=0.03$; women: $r=0.11, p=0.03$ ) and proximal femoral BMC (men: $r=0.16, p=0.0003$; women $r=0.16, p=0.0008$ ), although relationships with BMD were weaker and were significant only in men at the proximal femur ( $r=0.10, p=0.03$; Table 2). Relationships between birth weight and BMC remained significant at the proximal femur after adjustment for age, BMI, cigarette and alcohol consumption, physical activity, social class, years since menopause, and HRT use in women. Relationships between weight at $1 \mathrm{y}$ and $\mathrm{BMC}$ were significant at all sites measured and were stronger in men (lumbar spine: $r=0.17, p=0.0001$; proximal femur: $r=0.22, p<0.0001$ ) than women (lumbar spine: $r=0.13$, $p=0.01$; proximal femur: $r=0.14, p=0.002$; Table 3). These relationships remained significant after adjustment for age, BMI, cigarette and alcohol consumption, physical activity, social class, HRT use, and years since menopause in women. Relationships between weight at $1 \mathrm{y}$ and BMD were again weaker.

Figures 1 and 2 display the effect of partitioning the influence of birth weight, conditional weight in infancy, and adult weight on bone mass in later life, using ANOVA. Hence, in men, $17.8 \%$ of the variance in proximal femoral bone area is explained by a model that includes birth weight, conditional weight at $1 \mathrm{y}$, and adult weight, with the relative contributions 
Table 2. Relationship between bone mass and birth weight in 498 men and 468 women from the Hertfordshire 1931-1939 cohort

\begin{tabular}{|c|c|c|c|c|}
\hline $\begin{array}{l}\text { Correlation with } \\
\text { birth weight }\end{array}$ & \multicolumn{2}{|c|}{ Men } & \multicolumn{2}{|c|}{ Women } \\
\hline Area & $\begin{array}{c}0.12, p=0.01 \\
n=495\end{array}$ & $\begin{array}{c}0.17, p=0.0002 \\
n=495\end{array}$ & $\begin{array}{c}0.18, p=0.0001 \\
n=443\end{array}$ & $\begin{array}{c}0.26, p<0.0001 \\
n=467\end{array}$ \\
\hline BMC & $\begin{array}{c}0.10, p=0.03 \\
n=495\end{array}$ & $\begin{array}{c}0.16, p=0.0003 \\
n=495\end{array}$ & $\begin{array}{c}0.11, p=0.03 \\
n=443\end{array}$ & $\begin{array}{c}0.16, p=0.0008 \\
n=467\end{array}$ \\
\hline BMD & $\begin{array}{c}0.05, p=0.26 \\
n=497\end{array}$ & $\begin{array}{c}0.10, p=0.03 \\
n=495\end{array}$ & $\begin{array}{c}0.03, p=0.59 \\
n=468\end{array}$ & $\begin{array}{c}0.02, p=0.62 \\
n=467\end{array}$ \\
\hline
\end{tabular}

Table 3. Relationship between bone mass and weight at 1 year in 498 men and 468 women from the Hertfordshire 1931-1939 cohort

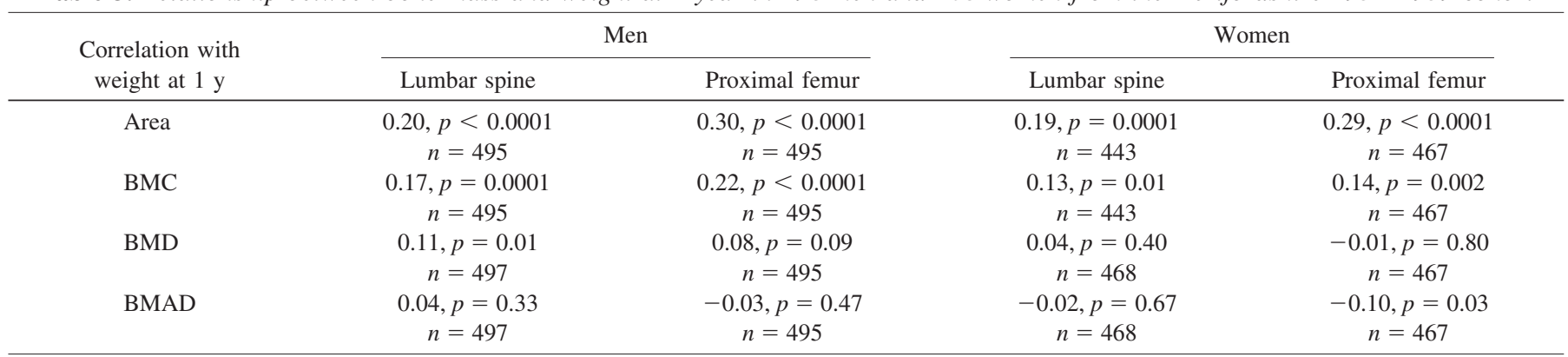

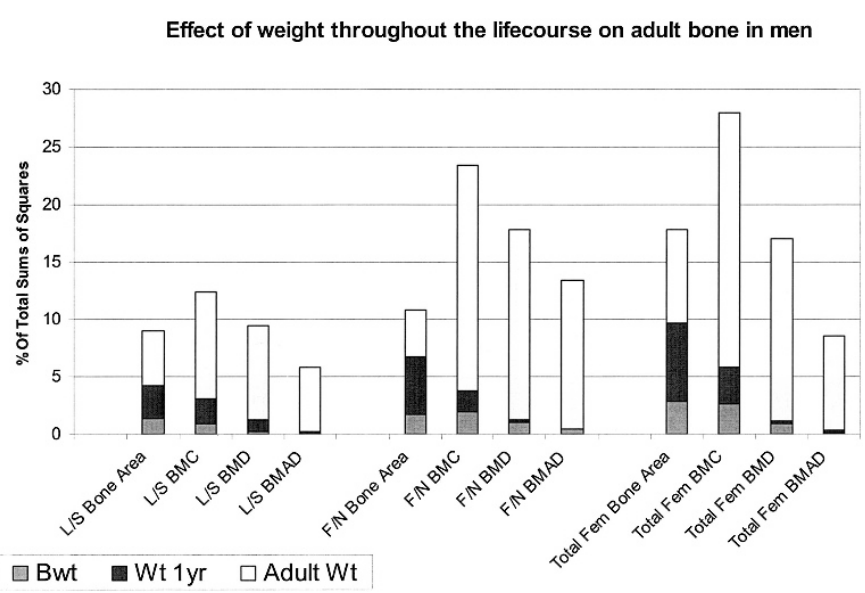

Figure 1. Partitioning of effects of weight throughout the life course on bone mass in Hertfordshire men, born 1931-1939.

attributed to each being $2.8,6.8$, and $8.2 \%$, respectively. In women, similar modeling produces figures of $6.7,4.2$, and $3.9 \%$ to an overall variance of $14.8 \%$ in proximal femoral bone area. Furthermore, $9 \%$ of the variance in male lumbar spine bone area is explained by a model that includes birth weight, conditional weight at $1 \mathrm{y}$, and adult weight, with the relative contributions attributed to each being 1.3, 2.8, and 4.8\%, respectively. In women, similar modeling produces figures of $3.4,1.5$, and $0.6 \%$ to an overall variance of $5.5 \%$ in lumbar spine bone area. Of note, there were no significant interactions between birth weight and weight at $1 \mathrm{y}$ as predictors of any bone mass measure at any site in either sex. Hence, weight at each measured point in the life course is important in the ultimate determination of adult bone mass, with greater contributions of earlier growth to bone area and BMC than BMD or BMAD. Addition of other factors (age, social class, physical activity, cigarette and alcohol consumption, menopausal status,

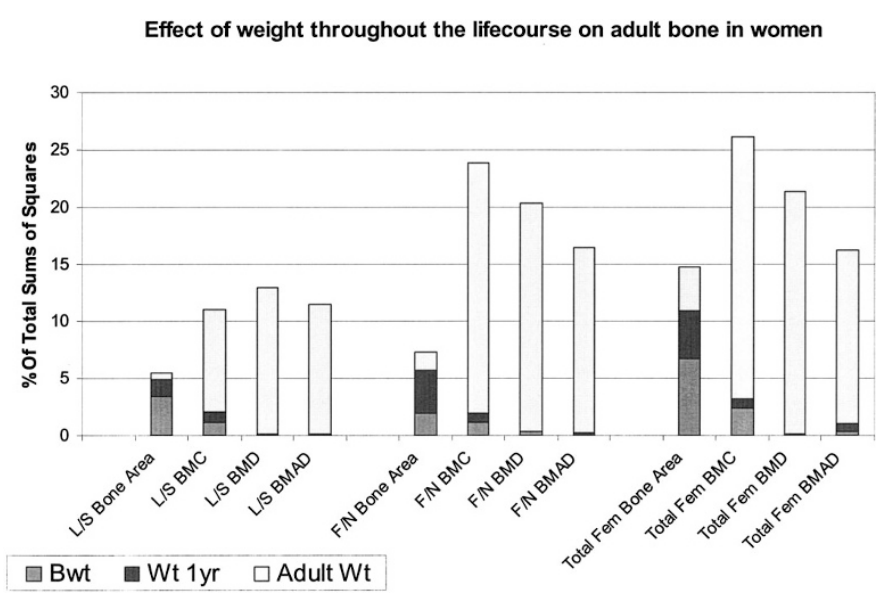

Figure 2. Partitioning of effects of weight throughout the life course on bone mass in Hertfordshire women, born 1931-1939.

and HRT use in women) contributed little to the model; hence, in men, addition of these factors contributed $2.2 \%$ to the variance at the total femur and $1.2 \%$ at the lumbar spine, whereas in women, the corresponding figures were 4.1 and $5.6 \%$.

A total of $112(15 \%)$ men and $130(18 \%)$ women from the whole cohort of 1482 individuals studied sustained fractures after the age of $45 \mathrm{y}$. We found no relationship between fracture and early life measures in this group.

\section{DISCUSSION}

We have found independent associations of both birth weight and weight at $1 \mathrm{y}$ with $\mathrm{BMC}$ in the seventh decade in both sexes, suggesting that both prenatal and postnatal factors may be important in determining the size of the skeletal envelope. As in previous studies, relationships between early life factors and adult BMD were much weaker, suggesting that 
lifestyle and genetic factors may be more important determinants of areal bone density and age-related bone loss. Although we did not show significant relationships between early life factors and fracture in this cohort, this may reflect the small number of low-impact fractures observed so far.

Our study has a number of weaknesses. The individuals recruited were selected because they had been born in Hertfordshire and continued to live there at the age of 60-75 y, as in previous studies. However, we have previously demonstrated that the Hertfordshire populations studied have similar smoking characteristics and bone density to national figures (10), suggesting that selection bias is minimal. Furthermore, we ascertained that those who did not complete the study had similar birth weights and weights at $1 \mathrm{y}$ to those who did not. We also confirmed that there were no significant differences in anthropometric measures, cigarette or alcohol consumption, or physical activity levels between those who did or did not elect to undergo a bone density test.

Initial studies from Bath showed a relationship between weight at $1 \mathrm{y}$ and $\mathrm{BMC}$ at age $21 \mathrm{y}$ in women (1), whereas further work in Hertfordshire went on to demonstrate an association between weight at $1 \mathrm{y}$ and BMC at age 60-75 y in both sexes (2). More recent data from the United States showed an association between recalled birth weight and BMC in 305 postmenopausal women (3). Typically, adjustment for adult weight or height weakens but does not remove this association. Similarly, data from Sheffield demonstrated significant associations between birth weight and adult BMC (and lean mass) after adjustment for age, sex, height, and physical activity (4). Available data therefore would support the hypothesis that different mechanisms exist for establishing the adult bone envelope, which encompasses not only the length of the bone but also its width (estimated by BMC) versus its density (estimated by BMD) versus its apparent volumetric density (estimated by BMAD). Each of these factors is important in establishing an individual's fracture risk. The independent effects of birth weight and weight at $1 \mathrm{y}$ suggest that although genetic and/or intrauterine environmental factors that influence the fetal growth trajectory and are reflected in birth weight have long-term consequences on bone mass in late adulthood, further modification of the infant growth trajectory over the first year of life has lasting effects on adult bone mass and hence fracture risk.

It is difficult to disentangle the influences of the genome and intrauterine environment on birth weight. In a family study performed 5 decades ago, Penrose suggested that $62 \%$ of the variation in birth weight between individuals was the result of the intrauterine environment, $20 \%$ was the result of maternal genes, and $18 \%$ was the result of fetal genes (11). In addition, studies of infants who were born after ovum donation showed that although their birth weights were strongly related to the birth weights of the recipient mother, they were unrelated to the weight of the female donors (12). Coupled with animal studies (13-15), these data suggest that birth size is controlled at least in part by the intrauterine environment rather than by the genetic inheritance from both parents. Finally, a recent study that examined the association of birth weight with bone mass in a twin study of $>4000$ women confirmed that bone mass and especially BMC were highly associated with birth weight in both monozygotic and dizygotic twins (16). These associations point to environmental rather than genetic factors underlying the observed relationships.

Adult bone mass is a function of both bone size and density (17); both of these variables influence fracture risk $(18,19)$. Both bone geometry and bone properties (including microarchitecture) are also known to be determinants of bone strength; with age, changes in the elastic modulus and toughness of bone are offset by periosteal apposition, which may help to preserve bone strength (20). BMD is limited at detecting fracture risk; although risk for fracture increases with decreasing BMD, many individuals fracture with a "normal" BMD. In part, this may reflect the limitations of DEXA in assessing bone density (by dividing BMC by projected bone area); projected bone area will systematically underestimate the skeletal bone volume of taller individuals; hence, the alternative ratio BMAD has been suggested (8). Recent work using computer models (21) has suggested that a $10 \%$ increase in peak BMD is predicted to delay the development of osteoporosis by $13 \mathrm{y}$, whereas a $10 \%$ change in the age at menopause or the rate of nonmenopausal bone loss is predicted to delay osteoporosis by $\sim 2 \mathrm{y}$, reinforcing the importance of peak bone mass in the cause of osteoporosis and fragility fractures. In a different approach, Tabensky et al. (22) performed a study of mothers and daughters to demonstrate reduced vertebral volumetric BMD among women who had sustained a vertebral fracture, reflecting reduced accrual of bone during growth in addition to reduced periosteal apposition during aging.

It has long been recognized that there are critical periods during mammalian development when exposure to specific environmental stimuli are required for normal development of structures or endocrine systems. The fetus seems to respond to insults during the prenatal period through the process of programming. Animal work to support this hypothesis in the cause of bone mass acquisition is now available; in rat offspring of mothers that were fed low-protein diets, bone area and BMC (but not BMD) were reduced in adult life. Maternal protein restriction was also associated with changes in the appearance of the epiphyseal growth plate in late adulthood among the offspring. Taken together, these observations suggest that maternal undernutrition in the rat might modify the responsiveness of cells in the growth plate to growth-promoting influences during intrauterine or early postnatal life (23). Furthermore, the rat model of maternal protein insufficiency has been used to investigate the cellular mechanisms in the programming of bone development; normal proliferation and differentiation of mesenchymal stem cells were delayed by maternal protein restriction in early life. In addition, with skeletal maturity, "catch-up" or a physiologic shift in bone cell activity was present in the low-protein group (24).

Our findings that the growth trajectory of the skeletal envelope is established in early life may reflect programming of the growth hormone/IGF-1 axis. We have previously reported associations between weight at 1 y of age and circulating $\mathrm{GH}$ concentration in an older Hertfordshire cohort (25), and indeed there is evidence from animal models that the pattern of $\mathrm{GH}$ concentration in adult life may be influenced by transient 
events in early postnatal life, including temporary dietary protein restriction in rats after weaning (26). Similarly, Bishop et al. (27) demonstrated higher BMC at a 5-y follow-up in preterm infants who were previously randomly assigned to human milk versus formula.

In conclusion, we have demonstrated independent effects of birth weight and weight at $1 \mathrm{y}$ on BMC in the seventh decade in both sexes. To our knowledge, this is the largest cohort with recorded birth weight and infant weight that has been studied in this way. Clinical event extraction from GP records would, in the future, allow us to assess whether these observed relationships translate into altered fracture risk.

Acknowledgments. We thank the men and women who participated in the study and the nurses and radiology staff who administered the bone density measurements. Computing support was provided by Vanessa Cox, and the manuscript was prepared by Gill Strange.

\section{REFERENCES}

1. Cooper C, Cawley M, Bhalla A, Egger P, Ring F, Morton L, Barker D 1995 Childhood growth, physical activity and peak bone mass in women. J Bone Miner Res 10:940-947

2. Cooper C, Fall C, Egger P, Hobbs R, Eastell R, Barker D 1997 Growth in infancy and bone mass in later life. Ann Rheum Dis 56:17-21

3. Yarbrough DE, Barrett-Connor E, Morton DJ 2000 Birth weight as a predictor of adult bone mass in postmenopausal women; the Rancho Bernardo Study. Osteoporos Int 11:626-630

4. Gale CR, Martyn CN, Kellingray S, Eastell R, Cooper C 2001 Intrauterine programming of adult body composition. J Clin Endocrinol Metab 86:267-272

5. Antoniades L, MacGregor AJ, Andrew T, Spector TD 2003 Association of birth weight with osteoporosis and osteoarthritis in adult twins. Rheumatology (Oxford) 42:791-796

6. Cooper C, Erikkson JG, Forsen T, Osmond C, Tuomilehto J, Barker DJ 2001 Maternal height, childhood growth and risk of hip fracture in later life: a longitudinal study. Osteoporos Int 12:623-629

7. Dallosso HM, Morgan K, Bassy EJ, Ebrahim SB, Fentem PH, Arie THD 1988 Levels of customary physical activity among the old and very old living at home. J Epidemiol Community Health 42:121-127

8. Carter DR, Bouxsein ML, Marcus R 1992 New approaches for interpreting projected bone densitometry data. J Bone Miner Res 7:137-145
9. Cole TJ 1995 Conditional reference charts to assess weight gain in British infants. Arch Dis Child 73:8-16

10. Egger P, Duggleby S, Hobbs R, Fall C, Cooper C 1996 Cigarette smoking and bone mineral density in the elderly. J Epidemiol Community Health 50:47-50

11. Penrose LS 1954 Some recent trends in human genetics. Caryologia 6:521-530

12. Brooks AA, Johnson MR, Steer PJ, Pawson ME, Adballa HI 1995 Birthweight: nature or nurture? Early Hum Dev 42:29-35

13. Lush JL, Hetzer HO, Culbertson CC 1934 Factors affecting birthweights of swine. Genetics 19:329-343

14. Cawley RH, McKeown T, Record RG 1954 Parental stature and birthweight. Am Hum Genet 6:448-456

15. Roberts DF 1986 The genetics of human growth. In: Falkner F, Tanner JM (eds) Human Growth. Plenum Press, New York, pp 113-143

16. Antoniades L, MacGregor AJ, Andrew T, Spector TD 2003 Association of birth weight with osteoporosis and osteoarthritis in adult twins. Rheumatology (Oxford) 42:791-796

17. Theintz G, Buchs B, Rizzoli R, Shosman D, Clavien H, Sizonenko PC et al 1992 Longitudinal monitoring of bone mass accumulation in healthy adolescents: evidence for a marked reduction after 16 years of age at the levels of lumbar spine and femoral neck in female subjects. J Clin Endocrinol Metab 75:1060-1065

18. Cummings SR, Marcus R, Palermo L, Ensrud KE, Genant HK, Study of Osteoporosis Fractures Research Group 1994 Does estimating volumetric bone density of the femoral neck improve the prediction of hip fracture? A prospective study. J Bone Miner Res 9:1429-1432

19. Gilsanz V, Boechat MI, Gilsanz R, Loro ML, Roe TF, Goodman WG 1994 Gender differences in vertebral sizes in adults: biomechanical implications. Radiology 190:678-682

20. Bouxsein ML 2003 Bone quality: where do we go from here? Osteoporosis Int 14(suppl 5):118-127

21. Hernandez CJ, Beaupre GS, Carter DR 2003 A theoretical analysis of the relative influences of peak BMD, age-related bone loss and menopause on the development of osteoporosis. Osteoporos Int 14:843-847

22. Tabensky A, Duan Y, Edmonds J, Seeman E 2001 The contribution of reduced peak accrual of bone and age-related bone loss to osteoporosis at the spine and hip: insights from the daughters of women with vertebral or hip fractures. J Bone Miner Res 16:1101-1107

23. Mehta G, Roach HI, Langley-Evans S, Taylor P, Reading I, Oreffo RO, Aihie-Sayer A, Clarke NM, Cooper C 2002 Intrauterine exposure to a maternal low protein diet reduces adult bone mass and alters growth plate morphology in rats. Calcif Tissue Int 71:493-498

24. Oreffo RO, Lashbrooke B, Roach HI, Clarke NM, Cooper C 2003 Maternal protein deficiency affects mesenchymal stem cell activity in the developing offspring. Bone 33:100-107

25. Fall C, Hindmarsh P, Dennison E, Kellingray S, Barker D, Cooper C 1998 Programming of growth hormone secretion and bone mineral density in elderly men: a hypothesis. J Clin Endocrinol Metab 83:135-139

26. Harel Z, Tannenbaum GS 1995 Long-term alterations in growth hormone and insulin secretion after temporary dietary protein restriction in early life in the rat. Pediatr Res 38:747-753

27. Bishop NJ, Dahlenburg SL, Fewtrell MF, Morley R, Lucas A 1996 Early diet of preterm infants and bone mineralisation at age five years. Acta Paediatr Scand $85: 230-236$ 